"Different centers can be very selective about patients, therefore there is a bias in the numbers," he claims. ASRM admits that this has been a common criticism: "the report is not as sophisticated as physicians would like it. The CDC has resolved to categorize results by age as a straightforward measure of success." There are other factors outside the physicians control that can affect the outcome of an ART treatment. For example, the length of time infertility has been a problem and the number of previous unsuccessful ART attempts. CDC's Lyn Wilcox stresses that the report is "not a journal research study and has its limitations. It provides one piece of the information you need to make an informed decision."

The 1992 law also called for the CDC to publish proposed standards for laboratories involved in ART in the Federal Register, which will be issued by the end of this month.

\section{Postponing pregnancy by freezing oocytes}

What do consumers want most from fertility treatments? "To make their eggs younger", says Margaret Hollister, Helpline director at RESOLVE-a consumer advocacy group for infertility. Although the statement was made jokingly, this possibility may not be too far off. While eggs obviously cannot be made younger, the ability to freeze oocytes-a technique initially developed for women facing surgery where ovaries will be removed or radiation therapy of the pelvis-is expected to become a routine procedure for healthy women who want to preserve eggs in a "younger" state for future use.

Infertility rates among women in the US have been increasing steadily, largely because women are postponing childbirth. A woman's fertility declines rapidly after age 35 and stops completely by the mid-forties. Until now the only hope of achieving pregnancy for some older women has been to rely on donor eggs. But last October, Atlanta-based Reproductive Biology Associates (RBA) reported the successful birth of twins from donor eggs that had been frozen for over two years - the first birth of its kind in the US. The mother, a 39-year-old woman suffering from premature ovarian failure, could have opted for fresh donor eggs but was encouraged to try a more experimental procedure in return for complete anonymity.

After the birth announcement, RBA's scientific director, Michael J. Tucker, says

that his clinic had to turn away 400-500 women who wanted to have their eggs frozen. Tucker has performed the technique on five patients using a more premature type of egg, a germinal vesicle oocyte, which appears to be more amenable to freezing, and has resulted in one pregnancy that so far appears normal by amniocentesis. But because the technique still has no proven track record and

is expensive (around $\$ 7,000$ per attempt), Tucker is reluctant to start offering it to healthy women who simply want to postpone pregnancy. Other physicians are not as cautious. Fertility Institutes of California announced in December that the clinic is offering the technique to healthy women and now has two pregnancies underway from frozen eggs.

LAURA BONETTA, NEW YoRK

\title{
Clinton's spending on AIDS-care goes awry
}

Two funding initiatives announced last month by the US department of Health and Human Services (HHS), which form part of President Clinton's second term spending spree on domestic issues, should bring relief to metropolitan areas hardest hit by HIV/AIDS. However, the new funds are seen only as an attempt at appeasement by AIDS activist groups, following the government's recent U-turn on plans to expand Medicaid coverage to include HIV positive patients.

On January 13th, the department of Health and Human Services (HHS) announced the distribution of $\$ 445$ million in grants under Title I of the Ryan White Comprehensive AIDS Resources Emergency (CARE) Act, to 49 of the neediest cities. The money is intended to cover healthcare and support services for low-income HIV/AIDS victims who lack medical insurance.

Five days later, the HHS announced a second grant program worth $\$ 39$ million, under Title III of the CARE Act. These dollars will support people with, or at risk of contracting, HIV. Money will go to selected clinics that experience heavy case loads and infection rates, where it will be used for diagnostic testing to determine HIV and immune status and for clinical services aimed at preventing and treating opportunistic infections and tuberculosis. HHS reports that funding for the Ryan White CARE Act-created in 1990 to help states, communities and families cope with the growing impact of AIDS-has increased 230 percent under the Clinton Administration. However, activist groups such as Gay Men's Health Crisis (GMHC) (New York City), say that this in no way compensates for the loss of expanded Medicaid access, which was promised but not delivered by the Administration last year. CARE programs, what they offer and their waiting lists, vary widely between States, Derek Link, director of Federal Affairs at GMHC told Nature Medicine. And unlike Medicaid-which is the primary federal health support program for low-income people-CARE does not provide access to the newest antiretroviral drugs that constitute the most vital part of HIV/AIDS treatment.

Currently, only people with full-blown AIDS qualify for Medicaid. Eligibility criteria became an issue last year when Vice President Al Gore announced that he would direct HHS to extend Medicaid access to people infected with HIV who are not yet clinically ill. Gore was attending a gala event in Washington D.C. and was receiving an award for his leadership on AIDS when he made the statement. But in December, HHS responded by saying that it would cost a minimum of $\$ 800$ million to provide the newest drugs to the additional 200,000 people that the expansion would encompass. The bottom line was that HHS refused Gore's request, saying it could not find a "revenue neutral" way to provide the medication.

Activists are furious. Not only because they believe the projected cost is an overestimate, but also because the recommended standard of care

Sheila foran for HIV is triple therapy at
earliest stage of infection. GMHC's the earliest stage of infection. GMHC's
Link blames in-fighting in the Clinton Administration for the Medicaid controversy: Gore had not consulted HHS before making his declaration and "the bureaucrats that run Medicaid were furious that elected leaders of the country would actually tell them what to do," he says. While Link acknowledges that altering Medicaid would require nothing short of a legislative change, he says this issue has been moved to the top of the agenda for AIDS groups around the country.

KAREN BIRMINGHAM, NeW YORK 